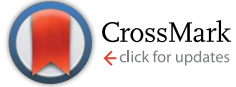

Cite this: J. Mater. Chem. A, 2016, 4, 16928

Received 20th July 2016

Accepted 30th September 2016

DOI: $10.1039 / c 6 t a 06133 h$

www.rsc.org/MaterialsA

\section{Morphologically and compositionally tuned lithium silicate nanorods as high-performance carbon dioxide sorbents $\uparrow$}

\author{
P. V. Subha, ${ }^{a}$ Balagopal N. Nair, ${ }^{\text {bc }}$ A. Peer Mohamed, ${ }^{a}$ G. M. Anilkumar, ${ }^{b}$ \\ K. G. K. Warrier, ${ }^{a}$ T. Yamaguchi ${ }^{d}$ and U. S. Hareesh ${ }^{\star a e}$
}

\begin{abstract}
The effective capturing of carbon dioxide using regenerable high capacity sorbents is a prerequisite for industrial applications aiming at $\mathrm{CO}_{2}$ capture and sequestration. The removal of $\mathrm{CO}_{2}$ directly from chemical reaction environments at high temperature is a less energy intensive method of its separation with the added benefit of improved efficiency in equilibrium limited reactions. However, the separation of $\mathrm{CO}_{2}$ at the typical reaction temperatures of $573-1073 \mathrm{~K}$ is a challenging task due to the nonavailability of absorbents with kinetics comparable to reaction rates. Moreover their poor durability due to sintering and particle growth on prolonged use at high temperature is also an impediment to their practical application. Herein, we demonstrate the development of an efficient $\mathrm{CO}_{2}$ absorbent material, made of $\mathrm{Li}_{4} \mathrm{SiO}_{4}$ nanorods, with ultrafast sorption kinetics as well as remarkable durability. These nanorods enabled easier surface reaction with $\mathrm{CO}_{2}$ due to shorter diffusion pathways for lithium from the bulk to the surface of the rods permitting extremely fast absorption of $\mathrm{CO}_{2}$. Furthermore, the compositional tuning of the materials helped to realize absorbents with extraordinary $\mathrm{CO}_{2}$ absorption rates of $0.72 \mathrm{wt} \% \mathrm{~s}^{-1}$ at $100 \% \mathrm{CO}_{2} / 923 \mathrm{~K}$. The exceptional performance of these absorbents at lower temperatures $(573-823 \mathrm{~K})$ as well as lower $\mathrm{CO}_{2}$ pressures $(0.15 \mathrm{~atm})$ demonstrates their potential in practical $\mathrm{CO}_{2}$ separation applications.
\end{abstract}

\section{Introduction}

Global warming and its effect on climate destabilization have grown into an alarming environmental concern in recent times. The massive consumption of fossil fuels leading to vast greenhouse gas emissions since the industrial revolution is believed to be the major reason for the current rise in atmospheric temperature. Green technological alternatives based on wind, solar and hydropower plants are therefore favored for minimizing carbon in the atmosphere. However, considering the cost and time frame required for the widespread implementation of such renewable

${ }^{a}$ Materials Science and Technology Division (MSTD), National Institute for Interdisciplinary Science and Technology, Council of Scientific and Industrial Research (CSIR-NIIST), Pappanamcode, Thiruvananthapuram, Kerala 695019, India.E-mail: hareesh@niist.res.in

${ }^{b} R \& D$ Centre, Noritake Company LTD, 300 Higashiyama, Miyoshi, Aichi 470-0293, Japan.E-mail: bnair@n.noritake.co.jp

'Nanochemistry Research Institute, Department of Chemistry, Curtin University, GPO Box U1987, Perth, Western Australia 6845, Australia

${ }^{d}$ Chemical Resources Laboratory, Tokyo Institute of Technology, Nagatsuta 4259, Midori-ku, Yokohama 226-8503, Japan

${ }^{e}$ Academy of Scientific and Innovative Research, Delhi-Mathura Road, New Delhi 110 025, India

$\dagger$ Electronic supplementary information (ESI) available: Experimental and supplementary figures and tables included. See DOI: 10.1039/c6ta06133h energy alternatives, an immediate solution appears remote. To reduce carbon footprints globally, a reduction in $\mathrm{CO}_{2}$ emission by maintaining a balanced carbon cycle in the atmosphere is imperative. Selective greenhouse gas capture and separation for reuse or sequestration thus emerge as a viable choice to limit its emission to the atmosphere. ${ }^{1}$ Among the strategies designed, $\mathrm{CO}_{2}$ capture using sorbents with appreciable absorption capacity, enhanced kinetics, selectivity, durability and cyclic stability together with a minimum energy penalty on the process appears practically viable at least in the short term. ${ }^{2-6}$

Removal of $\mathrm{CO}_{2}$ at high temperatures is an effective option to reduce its emissions to the atmosphere. ${ }^{7-9}$ In several hightemperature chemical and petrochemical processes, $\mathrm{CO}_{2}$ is a major product and its removal therefore at the temperature and pressure of the reaction offers a less energy intensive method of separation culminating in smaller carbon footprints. In reactions such as methane reforming, the removal of $\mathrm{CO}_{2}$ from the reaction vessel could also enhance the rate of reaction (sorption enhanced steam reforming) thereby providing additional benefits of increased productivity. ${ }^{\mathbf{1 0 , 1 1}}$ However, selective and rate enhanced sorption of $\mathrm{CO}_{2}$ at elevated temperatures is a challenging task, especially in the temperature range of 573$1073 \mathrm{~K}$ where most such reactions occur. Lithium based ceramic absorbents are considered as candidate materials for selective $\mathrm{CO}_{2}$ removal at high temperature, ${ }^{12-15}$ although their 
application is thus far limited by the slow kinetics in the lower temperature range (573-823 $\mathrm{K}$ ) and poor material durability in the higher temperature range (823-1073 K).

Among the lithium ceramics, lithium silicate $\left(\mathrm{Li}_{4} \mathrm{SiO}_{4}\right)$ based ceramic oxides are the most efficient $\mathrm{CO}_{2}$ sorbents by virtue of their high absorption capacity, faster kinetics and reasonable durability. ${ }^{16-19}$ The absorption properties of some of the recently published lithium-based ceramic absorbents are shown in Table S1 in section S1 of the ESI $\dagger^{+20-25}$ for a quick evaluation of the status. We also have reported on the sol-gel based synthesis of $\mathrm{Li}_{4} \mathrm{SiO}_{4}$ particles (powders termed as sol-gel in this manuscript) with $\mathrm{CO}_{2}$ absorption performance comparable to such published reports. ${ }^{26}$ In the work reported herein, we have adapted a facile microwave assisted sol-gel synthesis route ${ }^{27,28}$ to successfully realize $\mathrm{Li}_{4} \mathrm{SiO}_{4}$ nano-rods with significantly superior $\mathrm{CO}_{2}$ absorption performance. A detailed synthesis protocol starting from $\mathrm{LiNO}_{3}$ and colloidal silica is described under the experimental section. The powders thus obtained exhibited excellent $\mathrm{CO}_{2}$ absorption capacity, cyclic stability and superior absorption/desorption rates (powders termed as microwave sol-gel in this manuscript). We believe that the enhanced kinetics for $\mathrm{CO}_{2}$ absorption arise from the very small thickness $\left(20\right.$ to $30 \mathrm{~nm}$ ) of rod-shaped $\mathrm{Li}_{4} \mathrm{SiO}_{4}$ particles. Irrespective of their nano-size, the large aspect ratio of the particles provided them with better stability against aggregation at high working temperatures thereby providing improved durability for a large number of absorption/desorption cycles. Besides this, the compositional control of these morphologically tuned materials helped to realize novel eutectic compositions containing $\mathrm{Na}$ and $\mathrm{K}$ as new generation $\mathrm{CO}_{2}$ absorbents with exceptionally high $\mathrm{CO}_{2}$ absorption rates even at low and moderate temperatures $(<723 \mathrm{~K})$.

\section{Experimental}

\subsection{Synthesis of $\mathrm{Li}_{4} \mathrm{SiO}_{4}$ through a microwave sol-gel process}

$\mathrm{Li}_{4} \mathrm{SiO}_{4}$ was synthesised from $\mathrm{LiNO}_{3}$ (Alfa Aesar, UK) and colloidal silica (Aldrich Chemicals, USA) as the starting precursors. Initially $2.39 \mathrm{M} \mathrm{LiNO}_{3}$ solution was prepared by dissolving it in distilled water. Hydrolysis was carried out by the addition of $\mathrm{NH}_{4} \mathrm{OH}$ to the $\mathrm{LiNO}_{3}$ solution while stirring at room temperature. Colloidal silica was added dropwise under stirring for 1 hour to obtain a sol. The precursor sol was subjected to 700 $\mathrm{W}$ microwave radiation at $2.45 \mathrm{GHz}$ for $10 \mathrm{~min}$. A domestic microwave oven (Panasonic-NNGT231M) was used to carry out this experiment. The precursor was then dried at $423 \mathrm{~K}$ and heated to $1073 \mathrm{~K}$ at a ramp rate of $1{ }^{\circ} \mathrm{C} \mathrm{min}^{-1}$ in air atmosphere. The powder calcined at $1073 \mathrm{~K}$ for 3 hours was used for $\mathrm{CO}_{2}$ absorption studies unless specified otherwise.

\subsection{Processing of the mixture of $\mathrm{Li}_{4} \mathrm{SiO}_{4}$ and alkali carbonates}

$\mathrm{Na}_{2} \mathrm{CO}_{3}(99.9 \%), \mathrm{K}_{2} \mathrm{CO}_{3}(99.8 \%)$ and $\mathrm{Li}_{2} \mathrm{CO}_{3}$ (98\%), all from Merck, India, were mixed in the weight ratio of $10: 60: 30$ [eutectic-1], $32: 37: 31$ [eutectic-2] and $24: 45: 31$ [eutectic-3] and then blended with the microwave sol-gel samples in the weight ratio $1: 5$. The mixtures were then heat treated at $1073 \mathrm{~K}$ before the absorption studies at various temperatures.

\subsection{Characterization techniques}

Phase changes of the powder samples during heat treatment were traced using in situ HT-XRD (Rigaku RINT-TTR III). The morphology and crystallinity of the powders on $\mathrm{CO}_{2}$ absorption/ desorption were further characterised using TEM analysis (HRTEM, FEI Tecnai 30 G2 S-TWIN operated at an accelerating voltage of $300 \mathrm{kV}$ ). $\mathrm{CO}_{2}$ absorption properties were measured using a TGA apparatus (Perkin Elmer STA 6000, Singapore), in the temperature range of $100-750{ }^{\circ} \mathrm{C} . \mathrm{N}_{2}$ adsorption based surface area analysis was performed at $77 \mathrm{~K}$ using a Micromeritics Tristar 111 surface area analyser after degassing the sample at $200{ }^{\circ} \mathrm{C}$ for $2 \mathrm{~h}$.

\section{Results and discussion}

The morphological features of the synthesized particles at 673 $\mathrm{K}, 773 \mathrm{~K}$ and $1073 \mathrm{~K}$ are observed by TEM and are shown in Fig. 1a-f. Remarkably, the TEM images show that the particles have a nanorod morphology and are entirely different from the powders synthesized by conventional processing techniques. ${ }^{29,30}$ The XRD patterns of the microwave sol-gel $\mathrm{Li}_{4} \mathrm{SiO}_{4}$ samples after heat treatment (calcination) at $673 \mathrm{~K}, 773 \mathrm{~K}$ and $1073 \mathrm{~K}$ are further presented in Fig. $1 \mathrm{~g}$. From the XRD results, it is clear that the particles exhibited an amorphous nature even after calcination at $673 \mathrm{~K}$. Crystalline phases rich in the $\mathrm{Li}_{2} \mathrm{SiO}_{3}$ phase emerged only on increasing the temperature to $773 \mathrm{~K}$. Heat treatment at $1073 \mathrm{~K}$ was essential to realize $\mathrm{Li}_{4} \mathrm{SiO}_{4}$ phase (JCPDS file no. 37-1472) rich powders. The temperature dependent phase formation of the powders during the heat treatment of the synthesized particles has also been traced using in situ HT-XRD analysis and the results are detailed in section S2 of the ESI. $\dagger$ The results presented in Fig. $1 \mathrm{~g}$ and further in ESI $\mathrm{S} 2 \uparrow$ clearly revealed that the formation of the $\mathrm{Li}_{4} \mathrm{SiO}_{4}$ phase is achieved at the expense of $\mathrm{Li}_{2} \mathrm{SiO}_{3}$ nanofibers that are initially nucleated from the amorphous silica particles coated with the lithium species. From the XRD analysis (section S2, Fig. S1 of the ESI $\dagger$ ), it was inferred that microwave treatment has influenced the hydrolysis of $\mathrm{LiNO}_{3}$ to $\mathrm{LiOH}$. We believe that the formation of the $\mathrm{LiOH}$ phase during hydrolysis and further, the intermediate formation of $\mathrm{Li}_{2} \mathrm{SiO}_{3}$ fibers are critical steps in the successful formation of the $\mathrm{Li}_{4} \mathrm{SiO}_{4}$ nanorods (please see section S2 of the ESI $\dagger$ and the figures and video in the section for a detailed explanation of the phase and morphology formation mechanism). Small peaks corresponding to the $\mathrm{Li}_{2} \mathrm{SiO}_{3}$ phase are visible in Fig. $1 \mathrm{~g}$ as well as in Fig. S2 (ESI $\dagger$ ). Usually, such presence of the $\mathrm{Li}_{2} \mathrm{SiO}_{3}$ phase in small quantities is considered to be due to the reaction between $\mathrm{Li}_{4} \mathrm{SiO}_{4}$ and $\mathrm{CO}_{2}$ in air ${ }^{\mathbf{1} 26}$ while cooling after heat treatment or handling during XRD measurements. However, the presence of $\mathrm{Li}_{2} \mathrm{SiO}_{3}$ peaks in Fig. $\mathrm{S} 2 \dagger$ (in situ XRD spectra) indicates the existence of some amount of the lithium meta-silicate phase in our samples.

Based on the XRD and TEM results, $1073 \mathrm{~K}$ was used as the calcination temperature for obtaining samples with $\mathrm{Li}_{4} \mathrm{SiO}_{4}$ as 


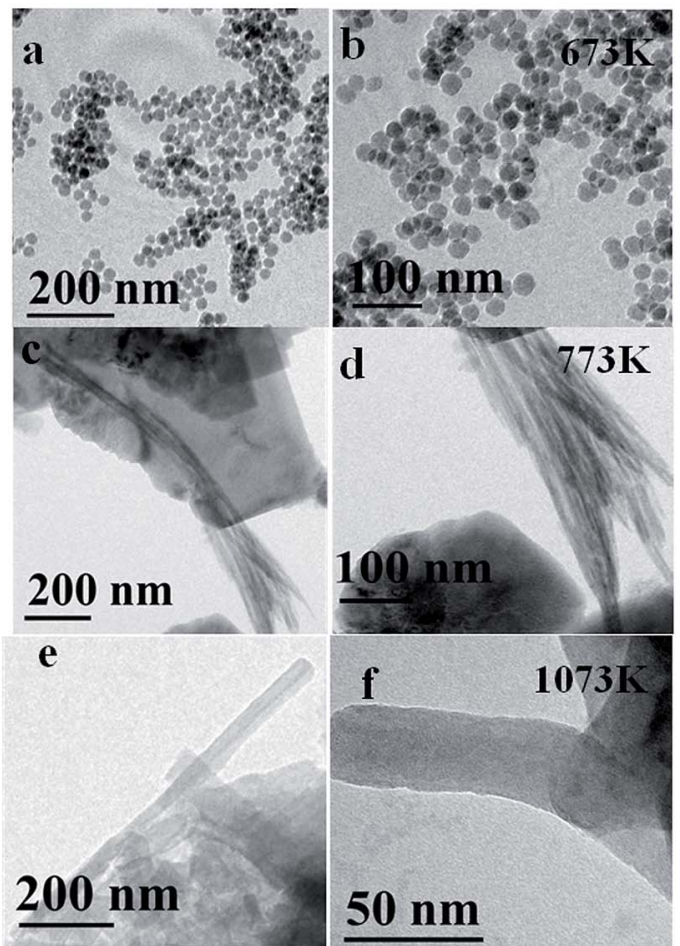

g

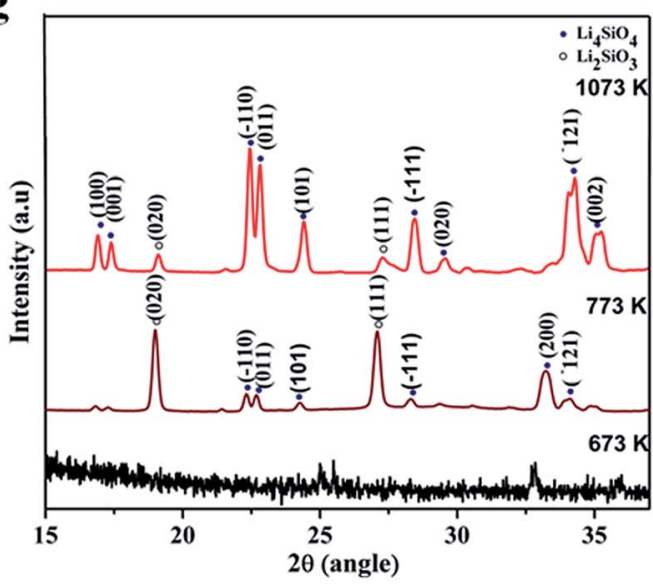

h

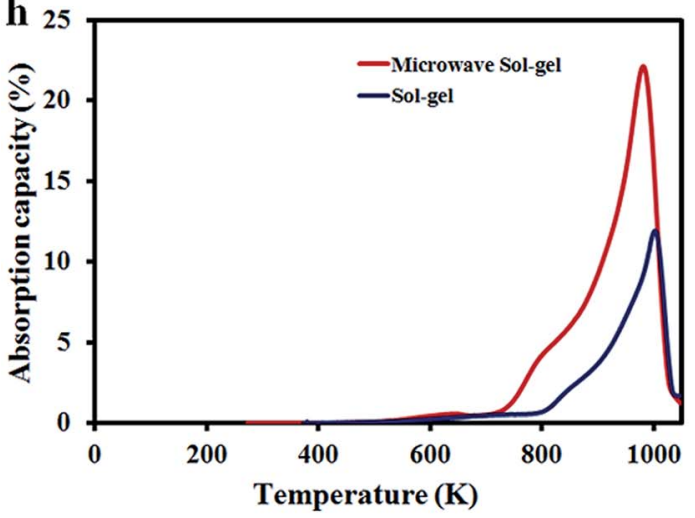

Fig. 1 TEM images of particles calcined at $673 \mathrm{~K}(\mathrm{a} \& \mathrm{~b}), 773 \mathrm{~K}(\mathrm{c} \& \mathrm{~d}$ ) and $1073 \mathrm{~K}$ (e $\&$ f). (g) XRD patterns of $\mathrm{Li}_{4} \mathrm{SiO}_{4}$ particles synthesized by a microwave sol-gel approach after calcination at temperatures of $673 \mathrm{~K}, 773 \mathrm{~K}$ and $1073 \mathrm{~K}\left(\mathrm{Li}_{4} \mathrm{SiO}_{4}, \mathrm{JCPDS} 37-1472\right)$, ( $\mathrm{Li}_{2} \mathrm{SiO}_{3}, \mathrm{JCPDS} 29-$ 0828). (h) Dynamic absorption curves of the microwave sol-gel powders in comparison to sol-gel $\mathrm{Li}_{4} \mathrm{SO}_{4}$ powders, measured at $20^{\circ} \mathrm{C}$ $\min ^{-1}\left(100 \% \mathrm{CO}_{2}\right)$. the predominant phase in our study. Unless otherwise mentioned, the samples named as "microwave sol-gel" in this manuscript are calcined at $1073 \mathrm{~K}$. The BET surface area analysis indicated a value of $7.3 \mathrm{~m}^{2} \mathrm{~g}^{-1}\left(\mathrm{~N}_{2}\right.$ adsorption isotherm is shown in section S3 of the ESI $\dagger$ ) for the particles.

We have initially performed a dynamic thermogravimetric analysis of microwave sol-gel $\mathrm{Li}_{4} \mathrm{SiO}_{4}$ particles under a $100 \%$ $\mathrm{CO}_{2}$ flow to determine the temperature range of gas absorption (Fig. 1h). For comparison, similar curves of powder samples prepared by the sol-gel method as reported elsewhere ${ }^{26}$ are also shown in Fig. 1h. As is clear from the dynamic absorption curves, the microwave sol-gel sample exhibited significant $\mathrm{CO}_{2}$ absorption capacity in the temperature range of $673-973 \mathrm{~K}$. The absorption is initiated at around $673 \mathrm{~K}$ leading possibly to the formation of an external shell of lithium carbonate $\left(\mathrm{Li}_{2} \mathrm{CO}_{3}\right)$ on the particle surface. This shell formation remained the main mechanism of absorption up to a temperature of about $823 \mathrm{~K}$. It is also evident from the figure that the rate of absorption increases at around $823 \mathrm{~K}$ and remains high till the reversible reaction occurs $(\sim 993 \mathrm{~K})$. The faster rate of absorption from $823 \mathrm{~K}$ is presumed to be due to the softening of the $\mathrm{Li}_{2} \mathrm{CO}_{3}$ shell, thereby decreasing the kinetic limitations imposed by the solid shell at lower temperatures. ${ }^{7}$ As mentioned, at $T>993 \mathrm{~K}$ the $\mathrm{Li}_{4} \mathrm{SiO}_{4}$ phase becomes stable, leading to the complete desorption of $\mathrm{CO}_{2}$. The absorption studies have thus confirmed that the microwave samples have superior $\mathrm{CO}_{2}$ absorption performances compared to sol-gel samples in the entire range of temperatures measured.

The morphological features of the microwave sol-gel based particles after $\mathrm{CO}_{2}$ absorption are shown in Fig. 2a and b. Compared to the original particles that exhibited rods of 20 to $30 \mathrm{~nm}$ width [Fig. $1 \mathrm{e}$ and $\mathrm{f}$ ], the particles after $\mathrm{CO}_{2}$ absorption appeared entirely different. As shown in Fig. 2a and b, the carbonate formation leads to the aggregation of the particles during the absorption stage. It can be inferred that the carbonate-rich particles, easily coalesce together forming a shell around a number of particles in the near vicinity, developing into an aggregate structure. However, desorption of $\mathrm{CO}_{2}$ leads to the reversible formation of individual $\mathrm{Li}_{4} \mathrm{SiO}_{4}$ particles, morphologically similar to the original samples (Fig. 2c and d). The morphological integrity of the particles after $\mathrm{CO}_{2}$ desorption process clearly evidences the stability of the nano-structures in the $\mathrm{CO}_{2}$ absorption/desorption cycle. The XRD patterns of the samples before and after $\mathrm{CO}_{2}$ absorption as well as after desorption are included in section $\mathrm{S} 4$ of the $\mathrm{ESI} \dagger$ for further analysis of the $\mathrm{CO}_{2}$ absorption/desorption process.

The $\mathrm{CO}_{2}$ absorption capacity values of the particles in the temperature range of 673-973 K are compared in Fig. 2e. For collecting the absorption data, the samples were heated to the absorption temperature at $10{ }^{\circ} \mathrm{C} \mathrm{min}^{-1}$ in $100 \% \mathrm{~N}_{2}$ gas and kept for $2 \mathrm{~h}$ under a $100 \% \mathrm{CO}_{2}$ gas flow. As expected, the amount of $\mathrm{CO}_{2}$ absorbed was found to increase with increase in the absorption temperature. This relationship between temperature and absorption capacity as well as the mechanism of absorption are better expressed using kinetic constants and activation energy values calculated from the Arrhenius plots of kinetic constants as shown in Fig. 2f. Further details on the 

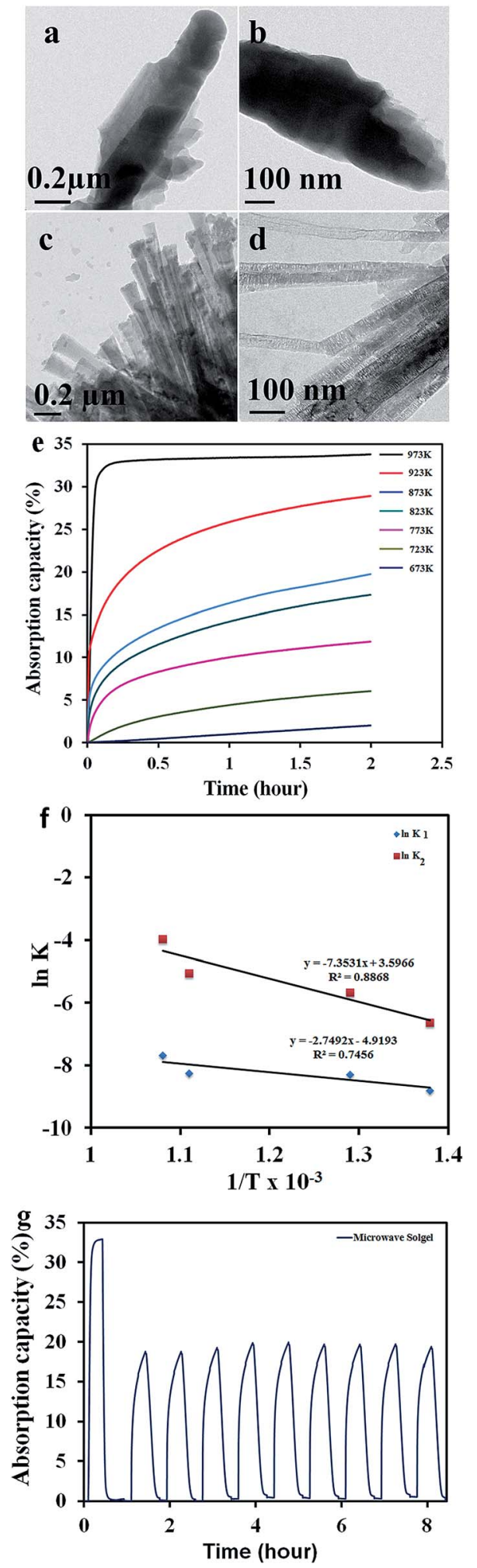

Fig. 2 TEM images (a and b) of microwave sol-gel $\mathrm{Li}_{4} \mathrm{SiO}_{4}$ particles after the $\mathrm{CO}_{2}$ absorption process; (c and d) particles after desorption process. (e) $\mathrm{CO}_{2}$ absorption curves at various temperatures. (f) Graph of $\ln K$ versus $1 / T$ for the two different processes of chemisorption $\left(K_{1}\right)$ and diffusion $\left(K_{2}\right)$ observed in the microwave sol-gel sample; $(g)$ absorption-desorption performance of microwave sol-gel $\mathrm{Li}_{4} \mathrm{SiO}_{4}$ powders for 10 cycles. The first cycle of the run was done at $973 \mathrm{~K}$ and further runs at $873 \mathrm{~K}$. In all cases, desorption was carried out by switching $100 \% \mathrm{CO}_{2}$ gas to $100 \% \mathrm{~N}_{2}$ gas. calculation of kinetic constants are included in section S5 of the ESI. $\dagger$ It should be noted that, contrary to the general trend, Fig. $2 \mathrm{f}$ indicates that the $K_{2}$ values are approximately 10 times larger than those of $K_{1}$. The larger $K_{2}$ values obtained here signifies faster lithium ion diffusion to the reaction interface compared to the chemisorption reaction. ${ }^{29}$ The activation energy values calculated from the plots were $22.70 \mathrm{~kJ} \mathrm{~mol}^{-1}$ for the chemisorption process (corresponding to $K_{1}$ ) and $61.10 \mathrm{~kJ}$ $\mathrm{mol}^{-1}$ for the diffusion process (corresponding to $K_{2}$ ). The higher activation energy value for the diffusion process substantiated the extremely fast diffusion of lithium ions from the core of the material to the reactive interface at absorption temperatures.

Absorption rates were also calculated from the first two minutes of absorption curves at different temperatures. The particles synthesised through a microwave sol-gel method displayed an enhanced absorption rate of $0.093 \mathrm{wt} \% \mathrm{~s}^{-1}$ at $973 \mathrm{~K}$. This value is much higher than the values reported in the recent literature (see table in ESI $\mathrm{S} 1 \uparrow$ for a comparison of some of the reported values). This enhanced absorption rate should mainly be attributed to the nano-rod morphology characterized by a very small thickness/width of the particle, facilitating a rapid surface carbonate layer formation over the entire length during the first stage of absorption. Moreover, the rod morphology should also have enabled easier surface reaction providing shorter diffusion pathways for lithium from the bulk to the surface of the particle.

The cyclic stability and regenerability of the powder samples were evaluated through cyclic absorption-desorption measurements and the results are shown in Fig. $2 \mathrm{~g}$ [absorption with $100 \% \mathrm{CO}_{2}$ and desorption with $100 \% \mathrm{~N}_{2}$ gases]. The primary aim of this cyclic loading experiment was to examine whether the sintering of the particles or the segregation of the carbonate phase due to continuous use of the absorbent at high temperatures induced any decay in absorption performance. The initial absorption run was done at $973 \mathrm{~K}$; thereafter the temperature of absorption was switched to $873 \mathrm{~K}$ and cyclic absorption-desorption performance for 9 consecutive cycles was recorded. The initial run at high temperature leading to more or less full conversion of the material to $\mathrm{Li}_{2} \mathrm{CO}_{3}$ and further to the $\mathrm{Li}_{4} \mathrm{SiO}_{4}$ phase helped to realize higher absorption values at $873 \mathrm{~K}$ (Fig. $2 \mathrm{e}$ and g). As shown in Fig. $2 \mathrm{~g}$ the samples displayed consistent absorption-desorption performance for all the 10 cycles measured indicating high durability and cyclic stability of the materials. Furthermore, it should be noted that the desorption rate was better than the absorption rate through all the measurements. The large desorption rate obtained without thermal cycling would allow the application of the materials for $\mathrm{CO}_{2}$ capture in pressure swing mode. Although, further cycling studies of thousands of cycles may be necessary before considering the material for real life applications, initial results as reported in Fig. $2 \mathrm{~g}$ indicated that the microwave solgel powders may be considered as promising materials for industrial absorption applications. Schematic illustrations comparing the carbon dioxide sorption and desorption mechanisms of $\mathrm{Li}_{4} \mathrm{SiO}_{4}$ nanoparticles and the newly developed nano rods, as well the influence of particle morphology on their 
durability are provided in Fig. 3a and b. The small thickness of the nanorods enables fast absorption kinetics just as in the case of nanoparticles. The better durability of the nanorod sample is highlighted based on ceramic sintering and particle coalescence mechanisms. It is well known that in liquid phase assisted sintering, the densification is achieved by the rearrangement and shape changes of the particles. Rearrangement is strongly affected by the size and morphology of the particles. Spherical and mono-dispersed particles are advantageous for particle rearrangement and sintering while particles like nanorods, having a high aspect ratio, are difficult to sinter. The Ostwald ripening/particle coalescence process invariably results in a reduction of the total surface area of the particles. $^{31,32}$ Hence the particle coarsening process as shown in Fig. $3 \mathrm{~b}$ of the schematic always leads to a reduction in absorption kinetics owing to the reduction of the absorbentgas interface available for chemisorption. In contrast, the use of higher aspect ratio $\mathrm{Li}_{4} \mathrm{SiO}_{4}$ nanorods impedes coalescence and agglomerate formation due to which it is possible to maintain high absorption kinetics even after several

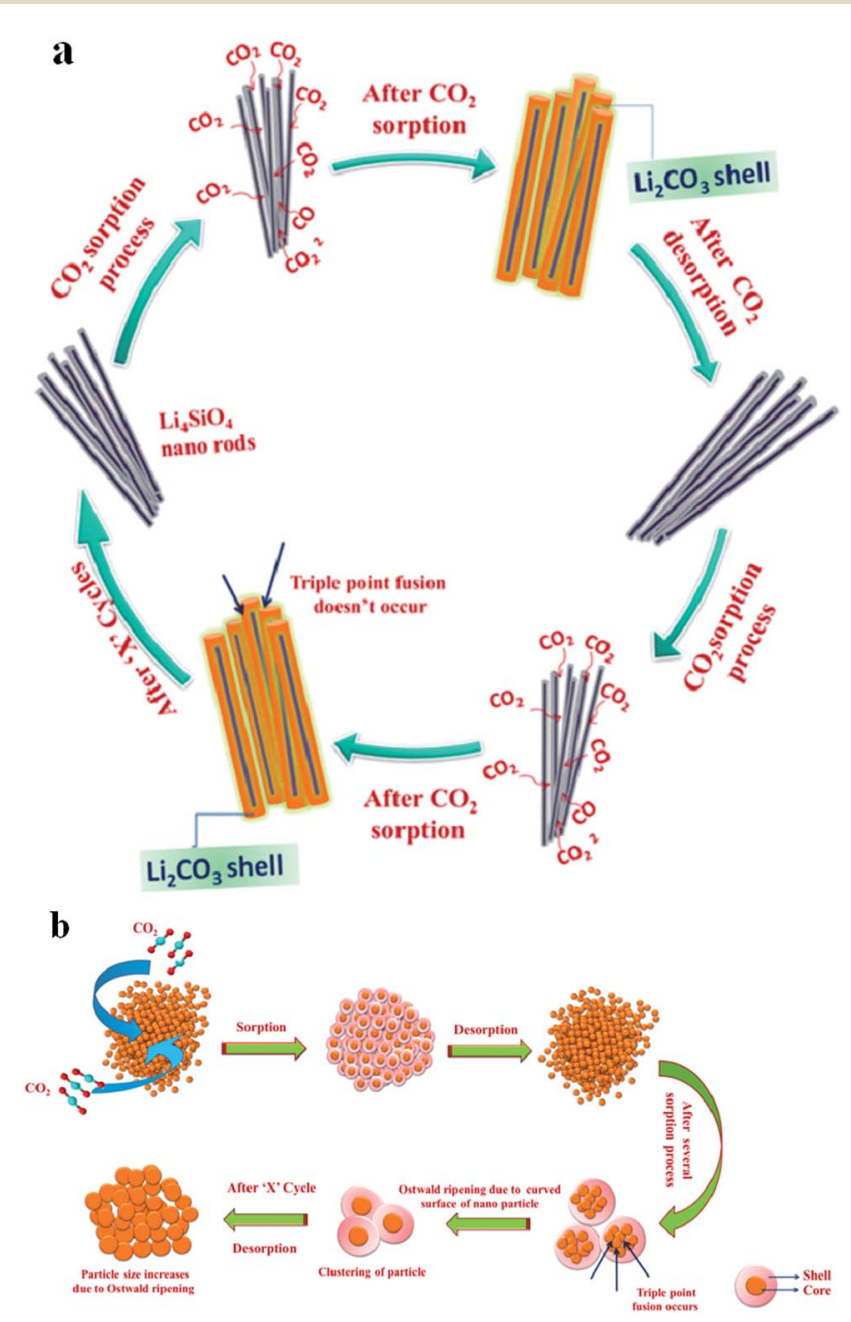

Fig. 3 Schematic illustrations comparing the carbon dioxide absorption and desorption mechanisms and the durability of (a) the newly developed $\mathrm{Li}_{4} \mathrm{SiO}_{4}$ nanorods and (b) commonly found $\mathrm{Li}_{4} \mathrm{SiO}_{4}$ nanoparticles. absorption/desorption cycles. The effects of morphological tuning on the kinetics of the carbon dioxide absorption process as well as the durability of the resulting particles are clearly depicted in the illustration.

Further, we tried to enhance the rate of absorption as well as the absorption capacity of the materials in the lowtemperature range by modifying the materials with a eutectic composition of mixed alkali carbonates. Carbonates of sodium, potassium and lithium were mixed in the weight ratio of $10: 60: 30$ [eutectic-1], 32:37:31 [eutectic-2] and $24: 45: 31$ [eutectic-3] and further blended with the microwave sol-gel samples in the weight ratio of $20: 80$. The mixtures were then heated to $1073 \mathrm{~K}$ before absorption studies. Fig. $4 \mathrm{a}$ and $\mathrm{b}$ present the TEM images of the eutectic- 3 sample obtained after the heat treatment process. The rod morphology of the sample is well maintained with the thickness varying from $40 \mathrm{~nm}$ to $100 \mathrm{~nm}$. The XRD pattern presented in Fig. 4c confirmed the presence of ortho- and metasilicates of lithium in addition to the alkali silicate phases of $\mathrm{Na}$ and K. A comparative evaluation of the dynamic absorption isotherms of the sol-gel, ${ }^{26}$ unmodified microwave sol-gel and microwave sol-gel samples modified with eutectic powder mixtures are presented in Fig. 4d. It is clear that the addition of eutectic mixtures increased the absorption capacity in the low-temperature range of $623-823 \mathrm{~K}$ significantly. In the unmodified samples, the rate of absorption was very low in the initial absorption step $(<823 \mathrm{~K})$ compared to the second absorption step. However, in the samples containing the eutectic mixtures the absorption rate in the initial step was comparable to that of the second absorption step. In the samples eutectic-1 and eutectic-2, two absorption steps are clearly visible as in the case of the unmodified sample. This is
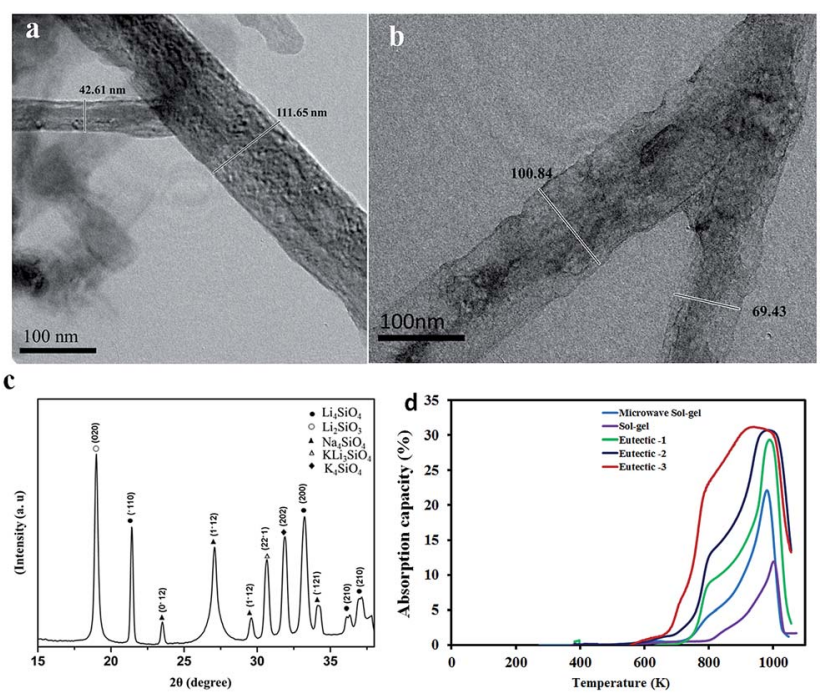

Fig. 4 TEM images (a $\&$ b) of the eutectic-3 particles. (c) X-ray diffraction patterns of eutectic-3 $\left[\mathrm{Li}_{4} \mathrm{SiO}_{4}, \mathrm{JCPDS} 37-1472\right],\left(\mathrm{Li}_{2} \mathrm{SiO}_{3}\right.$, JCPDS 29-0828), ( $\left.\mathrm{Na}_{4} \mathrm{SiO}_{4}, \mathrm{JCPDS} 072-0185\right),\left(\mathrm{KLi}_{4} \mathrm{SiO}_{4}, \mathrm{JCPDS} 038-\right.$ 0015), ( $\mathrm{K}_{4} \mathrm{SiO}_{4}$, JCPDS 046-0601). (d) Dynamic absorption curves of the sol-gel and microwave sol gel as well as eutectic 1, 2 and 3 samples. 
attributed to the carbonate shell formation, although a softer one compared to the unmodified sample, in these two cases. However, in the case of the eutectic-3 sample the two steps have combined to form a more or less single step absorption curve.

Detailed results of the $\mathrm{CO}_{2}$ absorption performance of the sample (eutectic-3) at temperatures of 623-923 K are shown in Fig. 5a. As shown, absorption capacity as high as 35\% could be observed at the temperature of $923 \mathrm{~K}$. It should be noted that the amount of $\mathrm{CO}_{2}$ adsorbed was higher than the value expected based on the stoichiometry of the reaction of one $\mathrm{CO}_{2}$ molecule with one orthosilicate available in the eutectic-3 sample (see Fig. 4c and 5a). It is possible that the reaction might have continued till silica is formed (instead of $\mathrm{Li}_{2} \mathrm{SiO}_{3}$ ) at least in some of the fractions of the powder mixture. Further studies are required to fully understand the chemisorption mechanism of these samples.

An enhanced absorption rate was observed at temperatures as low as $623 \mathrm{~K}$. Fig. 5b shows a good comparison of the absorption rates of the eutectic-3 sample with the unmodified microwave and sol-gel ${ }^{26}$ samples (calculated for the first 2 minutes of absorption). The rate of absorption observed for the eutectic-3 sample, $0.28 \mathrm{wt}^{\mathrm{m}} \mathrm{s}^{-1}$ at $923 \mathrm{~K}$, was significantly higher than the absorption rates measured with the unmodified microwave solgel and sol-gel samples. A comparison of the reported results (as shown in ESI S1 $\dagger$ ) including the most recent literature also shows that the absorption performance of the sample is exceptional. The $\mathrm{CO}_{2}$ absorption value of the sample, in fact, reached $>30 \mathrm{wt} \%$ within the first 42 seconds, based on which the absorption rate could be calculated to be $0.72 \mathrm{wt} \% \mathrm{~s}^{-1}$.

In order to find out the rate determining steps, the absorption curves (Fig. 5a) were fitted to the double exponential model and the resulting kinetic parameters were used to derive the Arrhenius plots as shown in Fig. 4c (further details are included in section $\mathrm{S} 5$ of the $\mathrm{ESI}_{\dagger}^{\dagger}$ ). It should be noted that the $K_{1}$ values are larger in this case compared to the $K_{2}$ values and this is contrary to the behaviour of the microwave unmodified samples. However, this is attributed to the presence of eutectic phases in the modified samples, which are supposed to enhance significantly the chemisorption rates. As a result, the modified and unmodified samples have different reaction limitations in the entire absorption process despite having more or less similar particle sizes. The activation energy values calculated from Fig. $5 \mathrm{c}$ were $82.3 \mathrm{~kJ} \mathrm{~mol}^{-1}$ and $205.18 \mathrm{~kJ} \mathrm{~mol}^{-1}$ for the chemisorption and diffusion processes, respectively. The activation energy for the chemisorption process was found to be much lower than that for the diffusion process. The sizes of sodium and potassium ions are larger compared to the lithium ions and, therefore, the whole diffusion process could be restricted in this case.

Cyclic absorption-desorption performances for 15 cycles at $948 \mathrm{~K}$ using $100 \% \mathrm{CO}_{2}$ and $100 \% \mathrm{~N}_{2}$ gases were recorded and the results are shown in Fig. 6a. As shown, the sample retained $>95 \%$ (33.6 wt \%) of its original absorption capacity even after 15 cycles at this very high temperature. Nevertheless, some structural and morphological changes are suspected as the shape of the absorption curve changed from a near perfect rectangle to
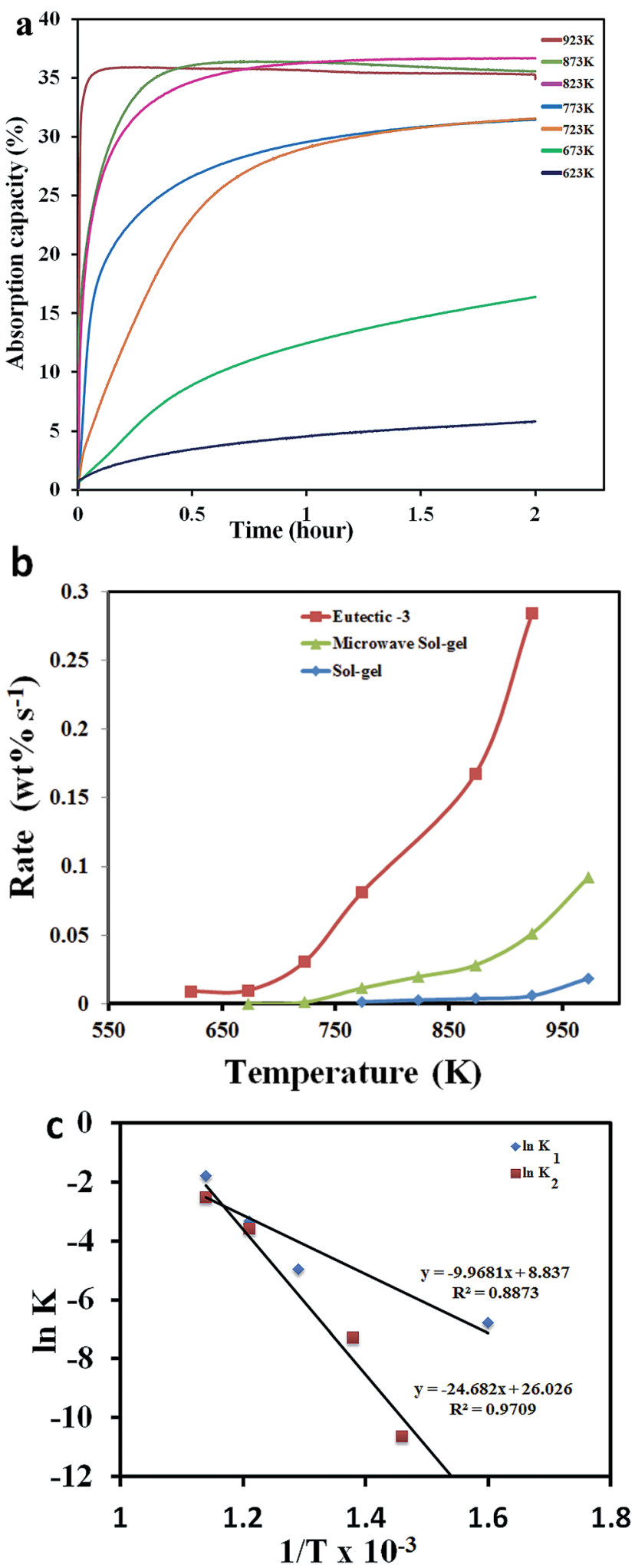

Fig. 5 (a) $\mathrm{CO}_{2}$ absorption curves of the eutectic mixture (eutectic-3) at various temperatures. (b) Absorption rates of eutectic-3 at different temperatures (rate values calculated from the initial two minutes of the absorption curve) in comparison to those of the microwave sol-gel and sol-gel samples. (c) Graph of In $K$ versus $1 / T$ for the two different processes of chemisorption $\left(K_{1}\right)$ and diffusion $\left(K_{2}\right)$ observed for the eutectic-3 sample. 
smoothed edges as the number of cycles increased. Further improvement in the stability of the powders may be necessary and techniques like the addition of rare-earth second phases as reported by us recently may be required..$^{30}$ As shown here and in Fig. 5a, the sample showed an absorption capacity of $\sim 35 \%$ for absorption temperatures $>823 \mathrm{~K}$ when the partial pressure of $\mathrm{CO}_{2}$ gas was $1 \mathrm{~atm}\left(100 \% \mathrm{CO}_{2}\right)$. Fig. $6 \mathrm{~b}$ shows the comparative absorption curves of eutectic-3 at $873 \mathrm{~K}$ for the $\mathrm{CO}_{2}$ partial pressure values of $1 \mathrm{~atm}\left(100 \% \mathrm{CO}_{2}\right)$ and $0.15 \mathrm{~atm}\left(15 \% \mathrm{CO}_{2} /\right.$ $85 \% \mathrm{~N}_{2}$ ). It is clear that the sample is capable of absorbing $\mathrm{CO}_{2}$ to $>25 \mathrm{wt} \%$ within the first few minutes of absorption even at the reduced $\mathrm{CO}_{2}$ partial pressure of $0.15 \mathrm{~atm}$.

It should be noted that the product streams of several hightemperature chemical reactions as well as the flue gases from power plants contain $15 \% \mathrm{CO}_{2}$. Therefore, the results indicate the possibility of using the developed materials for practical applications of $\mathrm{CO}_{2}$ capture. This exceptional absorption behavior of eutectic-3 should be due to the morphological as well as compositional features of this sample. With regard to the kinetics and $\mathrm{CO}_{2}$ absorption capacity, these morphologically and compositionally tailored particles outperform other structured lithium silicate particles reported in the recent literature (data from the literature is shown in the section S1 of the ESI $\dagger$ ).
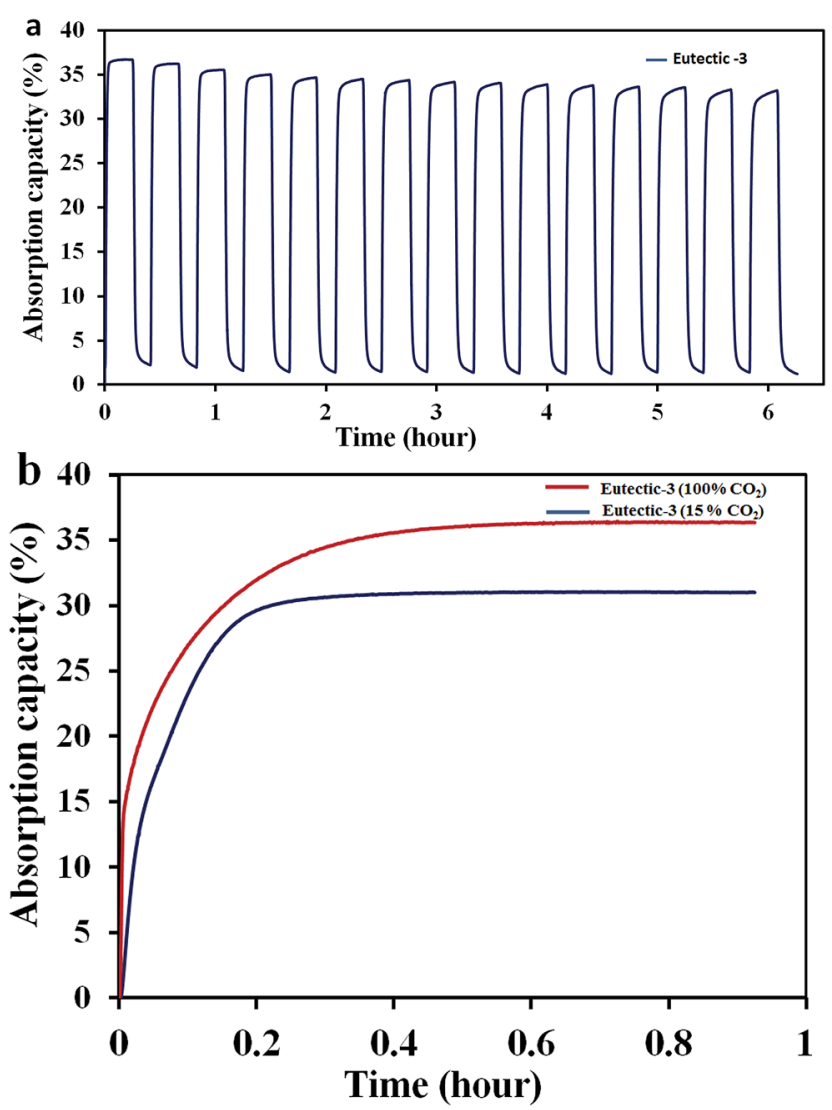

Fig. 6 (a) Cyclic absorption-desorption performance of eutectic-3 (absorption was carried out at $948 \mathrm{~K}$ and desorption at the same temperature by changing $100 \% \mathrm{CO}_{2}$ to $100 \% \mathrm{~N}_{2}$ gas). (b) Comparison of the absorption curves of eutectic-3 with $100 \% \mathrm{CO}_{2}$ flow and with $15 \% \mathrm{CO}_{2}$ flow. Absorption was carried out at $873 \mathrm{~K}\left(15 \% \mathrm{CO}_{2}\right.$ or $100 \%$ $\left.\mathrm{CO}_{2}\right)$.

\section{Conclusions}

In conclusion, a microwave assisted sol-gel synthetic approach is demonstrated for the synthesis of $\mathrm{Li}_{4} \mathrm{SiO}_{4}$ particles with a nanorod morphology. The nanorods exhibited a dramatically enhanced absorption rate for $\mathrm{CO}_{2}$ along with exceptional durability. The nanorod morphology of the $\mathrm{Li}_{4} \mathrm{SiO}_{4}$ particles allowed ultrafast sorption kinetics due primarily to an easier surface reaction with $\mathrm{CO}_{2}$ by virtue of shorter diffusion pathways for lithium from the bulk to the surface of the rods. In addition, the large aspect ratio of the nanorods helped to enhance the durability of the particles by limiting their Ostwald ripening upon high-temperature cyclic absorption/desorption loading. Further, we have modified the chemical composition of the $\mathrm{Li}_{4} \mathrm{SiO}_{4}$ particles by mixing them with a eutectic mixture of $\mathrm{K}$ and $\mathrm{Na}$. This compositional control of the materials helped to realize absorbents with extraordinary $\mathrm{CO}_{2}$ absorption rates of $0.72 \mathrm{wt}^{2} \mathrm{~s} \mathrm{~s}^{-1}$ at $100 \% \mathrm{CO}_{2} / 923 \mathrm{~K}$. Cycling absorption-desorption studies of these powders revealed that the materials remain durable up to 15 cycles without any significant reduction in $\mathrm{CO}_{2}$ absorption capacity. Furthermore, the modified samples showed remarkable absorption performance at lower temperatures $(573-823 \mathrm{~K})$ as well as lower $\mathrm{CO}_{2}$ pressures $(0.15 \mathrm{~atm})$ demonstrating their potential in practical $\mathrm{CO}_{2}$ separation applications.

\section{Acknowledgements}

The authors acknowledge the Council of Scientific and Industrial Research (CSIR), New Delhi, India, \& Noritake Co. Limited, Aichi, Japan, for providing research facilities and financial support. The authors acknowledge Mr Kiran Mohan for TEM analyses and Dr Bhoje Gowd and Mr N. Prithviraj for XRD analyses.

\section{Notes and references}

1 M. Kato, S. Yoshikawa and K. Nakagawa, J. Mater. Sci. Lett., 2002, 21, 485-487.

2 J. Wang, L. Huang, R. Yang, Z. Zhang, J. Wu, Y. Gao, Q. Wang, D. O'Hare and Z. Zhong, Energy Environ. Sci., 2014, 7, 3478-3518.

3 B. N. Nair, R. P. Burwood, V. J. Goh, K. Nakagawa and T. Yamaguchi, Prog. Mater. Sci., 2009, 54, 511-541.

4 D. M. D'Alessandro, B. Smit and J. R. Long, Angew. Chem., Int. Ed., 2010, 49, 6058-6082.

5 L. Joos, K. Lejaeghere, J. M. Huck, V. Van Speybroeck and B. Smit, Energy Environ. Sci., 2015, 8, 2480-2491.

6 M. Zaman and J. H. Lee, Korean J. Chem. Eng., 2013, 30, 14971526.

7 A. Samanta, A. Zhao, G. K. H. Shimizu, P. Sarkar and R. Gupta, Ind. Eng. Chem. Res., 2012, 51, 1438-1463.

8 J. Ortiz-Landeros, I. C. Romero-Ibarra, C. Gomez-Yanez, E. Lima and H. Pfeiffer, J. Phys. Chem. C, 2013, 117, 63036311.

9 B. N. Nair, T. Yamaguchi, H. Kawamura, S. I. Nakao and K. Nakagawa, J. Am. Ceram. Soc., 2004, 87, 68-74. 
10 C. Wang, Y. Chen, Z. Cheng, X. Luo, L. Jia, M. Song, B. Jiang and B. Dou, Energy Fuels, 2015, 29, 7408-7418.

11 M. S. Yancheshmeh, H. R. Radfarnia and M. C. Iliuta, Chem. Eng. J., 2016, 283, 420-444.

12 Y. Duan, H. Pfeiffer, B. Li, I. C. Romero-Ibar, D. C. Sorescu, D. R. Luebke and J. W. Halley, Phys. Chem. Chem. Phys., 2013, 15, 13538-13558.

13 H. Xu, W. Cheng, X. Jin, G. Wang, H. Lu, H. Wang, D. Chen, B. Fan, T. Hou and R. Zhang, Ind. Eng. Chem. Res., 2013, 52, 1886-1891.

14 T. Yamaguchi, T. Niitsuma, B. N. Nair and K. Nakagawa, J. Membr. Sci., 2007, 294, 16-21.

15 R. Rodriguez-Mosqueda and H. Pfeiffer, J. Phys. Chem. A, 2010, 114, 4535-4541.

16 K. Wang, X. Guo, P. Zhao, F. Wang and C. Zheng, J. Hazard. Mater., 2011, 189, 301-307.

17 J. Du and L. R. Corrales, J. Mater. Chem. B, 2006, 110, 2234622352.

18 K. Essaki, M. Kato and H. Uemoto, J. Mater. Sci., 2005, 40, 5017-5019.

19 M. Seggiani, M. Puccini and S. Vitolo, Int. J. Greenhouse Gas Control, 2011, 5, 741-748.

20 H. Kim, H. D. Jang and M. Choi, Chem. Eng. J., 2015, 280, 132-137.
21 J. H. Lee, B. Moon, T. K. Kim, S. Jeoung and H. R. Moon, Dalton Trans., 2015, 44, 15130-15134.

22 K. Wang, X. Y. Wang, P. F. Zhao and X. Guo, Chem. Eng. Technol., 2014, 37, 1552-1558.

23 S. Shan, S. Li, Q. Jia, L. Jiang, Y. Wang and J. Peng, Ind. Eng. Chem. Res., 2013, 52, 6941-6945.

24 V. L. Mejía-Trejo and E. Fregoso-Israel, Chem. Mater., 2008, 20, 7171-7176.

25 R. Quinn, R. J. Kitzhoffer, J. R. Hufton and T. C. Golden, Ind. Eng. Chem. Res., 2012, 51, 9320-9327.

26 P. V. Subha, B. N. Nair, P. Hareesh, A. Peer Mohamed, T. Yamaguchi, K. G. K. Warrier and U. S. Hareesh, J. Mater. Chem. A, 2014, 2, 12792-12798.

27 H. Pfeiffer, P. Bosch and S. Bulbulian, Synthesis of lithium silicates, J. Nucl. Mater., 1998, 257, 309-317.

28 B. N. Nair, K. Keizer, T. Okubo and S. I. Nakao, Adv. Mater., 1998, 10, 249-252.

29 M. J. Venegas, E. Fregoso-Israel, R. Escamilla and H. Pfeiffer, Ind. Eng. Chem. Res., 2007, 46, 2407-2412.

30 P. V. Subha, B. N. Nair, P. Hareesh, A. Peer Mohamed, T. Yamaguchi, K. G. K. Warrier and U. S. Hareesh, J. Phys. Chem. C, 2015, 119, 5319-5326.

31 G. Cao, Nanostructures \& Nanomaterials. Synthesis, Properties and Applications, Imperial College Press London, 2004.

32 M. Prokesova and Z. Panek, Ceram. Int., 1989, 15, 369-374. 